\title{
Turning research into art
}

$\mathrm{T}$ his project began two years ago in the basement of a community organization. The room was lit with the yellow glare of bright fluorescent lights, which reflected starkly off pale green walls. I sat in the midst of a ring of women who looked uncertainly back at me. When I met their eyes, I could read the distrust that lay within. These women were guarded - and with good reason. They were undocumented immigrants. They lived lives below the public radar and none had ever been approached to participate in a research study. I sat with them explaining the reasons why I wanted to understand their experiences in the Canadian health care system.

The Canadian Border Services Agency considers undocumented immigrants to be in the country illegally. All the participants in this study their experience accessing health care - information that is crucial to improving their health.

The women were disbelieving and cautious: Why did anyone in Canada care about their experiences accessing

\section{Stories of rape, of torture and of violence were challenging to hear and to tell.}

were being actively sought by the agency for deportation. For obvious reasons there is scant literature about undocumented immigrants in Canada and there is even less information about

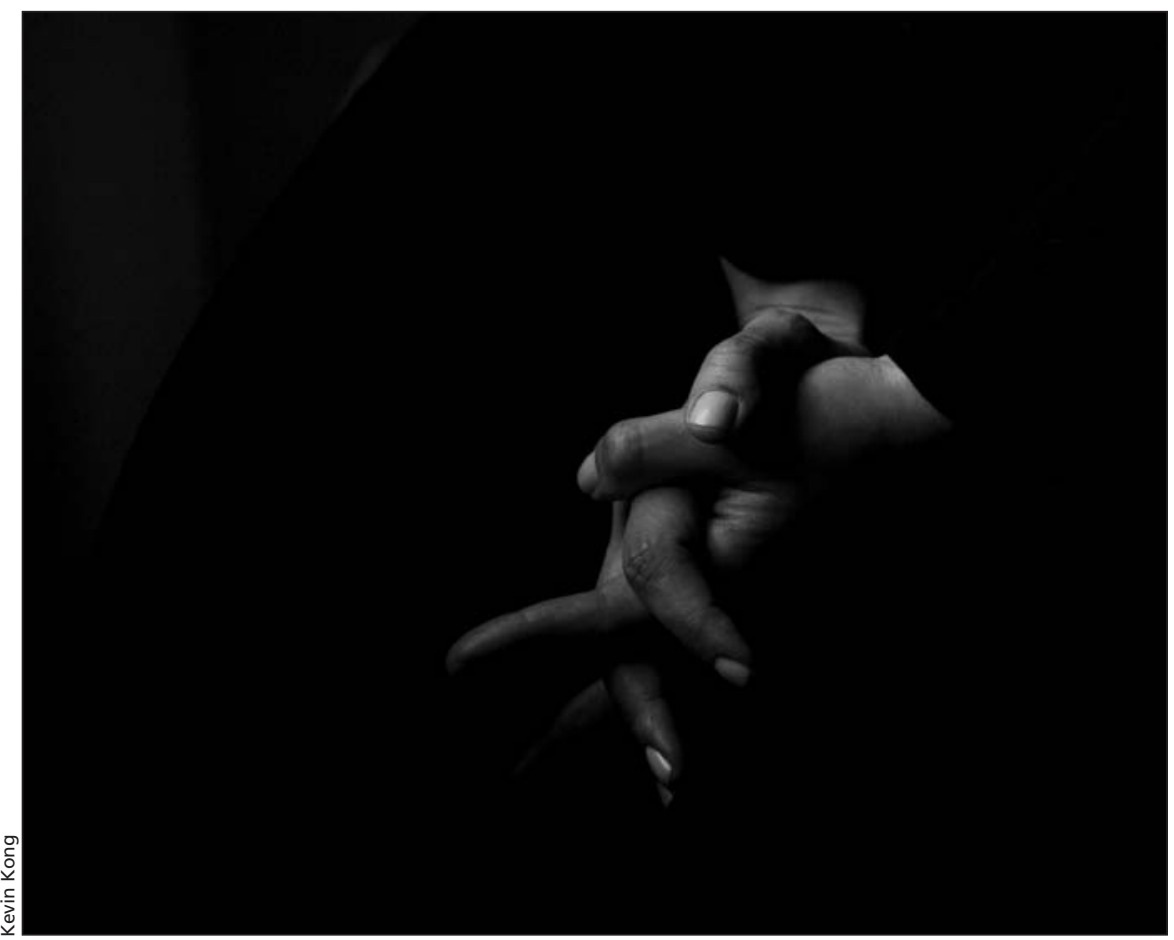

In this photograph, hands express humanity without revealing identity. These hands could be in prayer, grieving or tormented, but the fingers can also be seen as pathways to darkness. The subject's humanity is surrounded, isolated by the pervasive darkness, a solitary expression against despair or simply the unknown.

The participant (U13) states: "In my country I would pray every day. In Canada I don't even know how to pray anymore. I have lost everything and my God has lost me."

Its relevance to research: The lives of these women are wrought with trauma. Many of the women have experienced rape, torture and intimate partner violence. Their lives are convoluted and uncertain. Most struggle with the difficulties of moving forward in a linear, purposeful, healthy way.

health care? Their encounters with people in positions of authority - doctors, the police, health professionals and immigration officials - were, to say the least, not good. It took months to establish relationships with these women, but many ultimately agreed to participate in the group meetings and one-on-one interviews that formed the basis of the research study.

The broader study involved three groups of immigrants: six refugee claimants, six permanent residents and nine undocumented immigrants. Not surprisingly, the undocumented immigrants reported substantially greater problems accessing health care. The official system was the option of last resort; often these women sought black market health care. They had notable, unresolved mental health issues and many were victims of domestic abuse. They talked of the trauma of being chased by Canadian immigration officials, how they feared being reported by the police or health care professionals should they seek treatment in emergency departments, and their struggles with dental health and food security. Stories were shared of the events that provoked them to seek shelter in Canada. Horrific stories of rape, of torture and of violence in their home countries were challenging for both me to hear and for the women to tell; they were touching on raw, unresolved traumatic issues that resurrected suppressed images and emotions. 


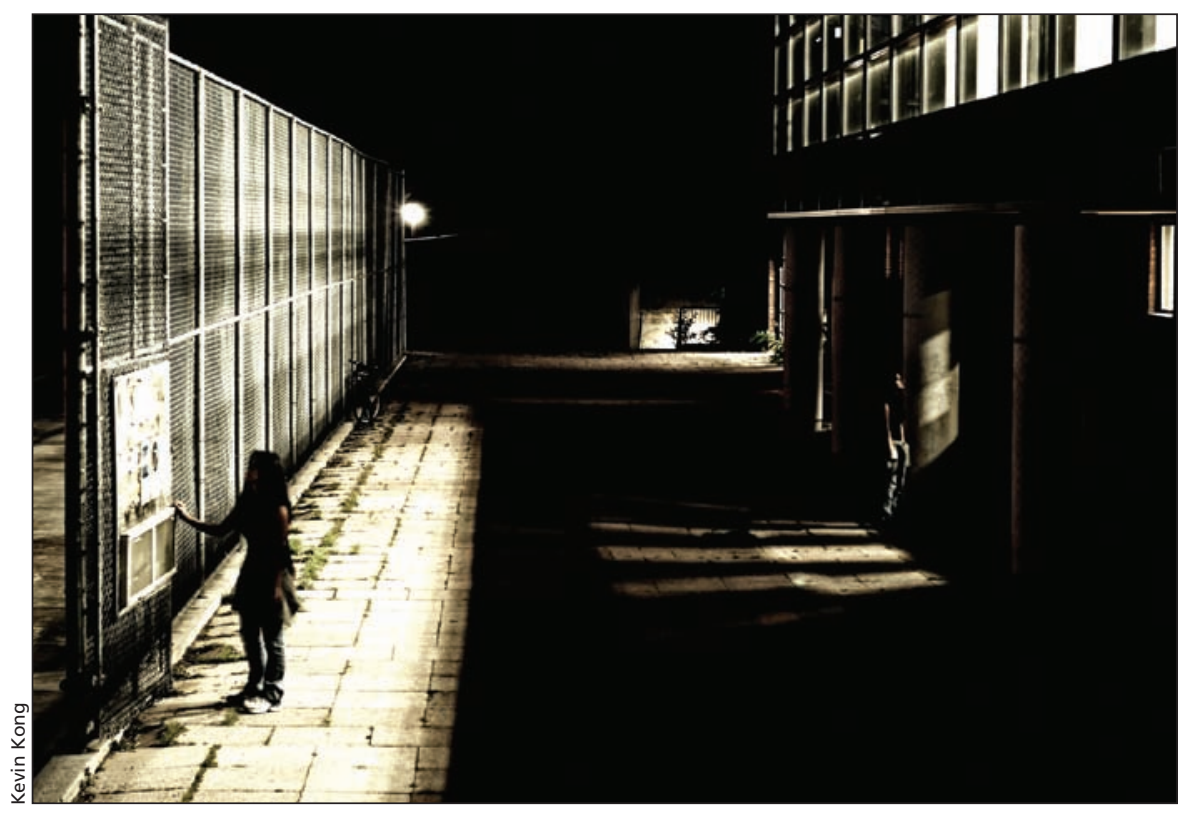

In this photograph, a lone subject is bordered on both sides by oppressive structures. Light areas reveal barriers; the darkness is only broken by uninviting geometry and a principally shadowed figure. The image's verticality looms oppressive and makes the subject small and directionless. She stands on the precipice of the image but nothing moves her towards or away from it.

The participant (U12) states: "I got the money to escape my country and come to Canada. But, I am not safe here either. The problem is this time I can't see the way forward. I am completely paralyzed ... I am sure there is a way out, or at least a way to move on, but I can't see it."

Its relevance to research: The women often spoke of being watched and expressed fear of entrapment. They receive little support, live lonely, secret lives and are concerned about being exposed. Fears of being caught, jailed and deported are constant.

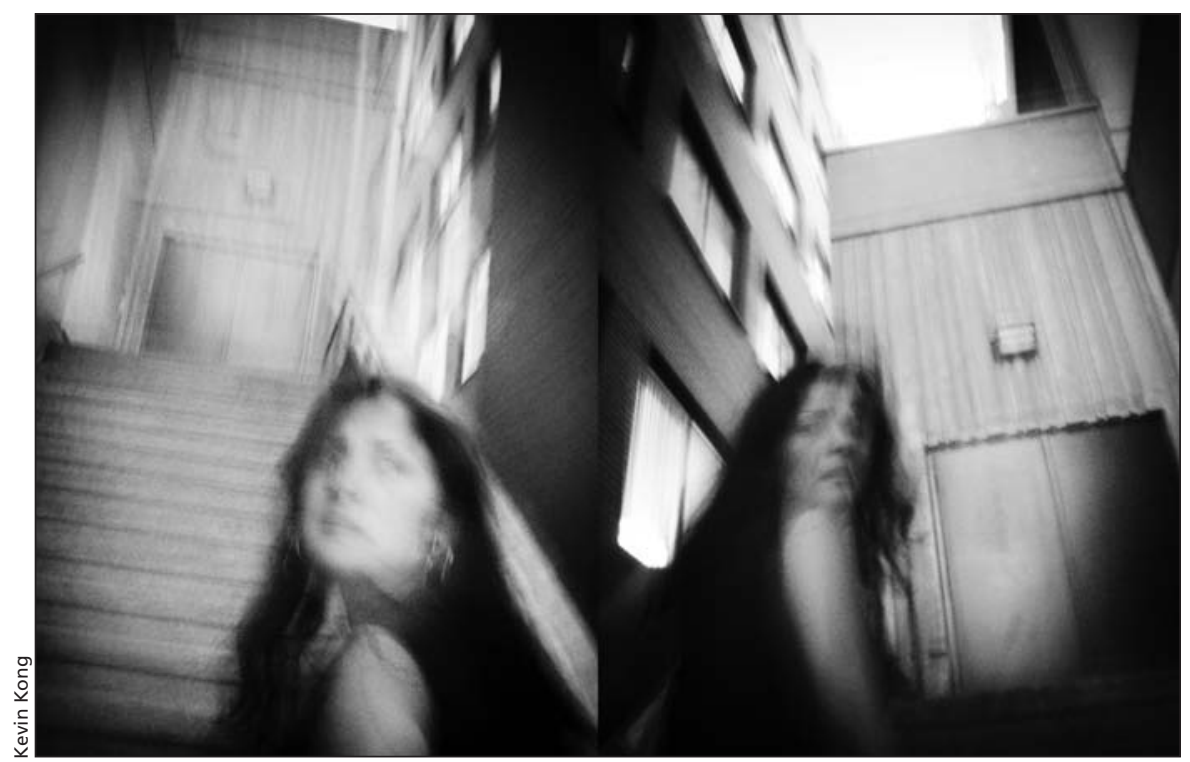

In this photograph, the subject is dominated by structures and the environment itself. She is in motion but the motion is undirected and erratic, pitting her against the world and herself.

The participant (U14) states: "I started running many years ago. I ran from my abusive husband. I ran to Canada. Now I run from the CBSA (Canadian Border Services Agency), the police and the doctors who try to report me. I am exhausted. All I wish is for sleep ... deep sleep without nightmares."

Its relevance to research: One of the themes of the research study was mental health issues. The women expressed the omnipresent fear that permeates their minds and the impermanence of their lives in Canada. They spoke of "the demons" that exist in their minds, relics of past and present trauma.
Toward the end of the data collection, the participants and I were sitting in a circle discussing next steps for the research, when one of them addressed me through the interpreter:

It is great that you like words, Ruth. I know doctors and researchers like words. You aren't capturing everything though ... We [the participants] have been talking. We want to do an art project to capture this. Then maybe your colleagues at the hospital, doctors, policemen and the public will understand us.

Based on this discussion, I established a photography team led by photographer Kevin Kong and supported by my two research assistants who had a trusting relationship with the women. The women worked with Kevin to transform hundreds of pages of research transcripts into images. Kevin took photographs in their homes and at places that held meaning for the women. Some photographs depict the food banks that denied them access because they lacked the required identification. Others capture an emotion, an experience, an object of significance or unidentifiable parts of their faces. The women then selected a series of twenty images that conveyed the essence of the emotions and experiences they had endured.

We are now looking for funding and support to help us stage this photography exhibition.

This exhibition will be their way of speaking to the public and to the doctors, health professionals, police and immigration officials who have shaped their experience of health and illness in Canada. Their inspiration and drive has led the project through a metamorphosis. Two years on from that starkly lit, green basement, research has been turned into art and art will, hopefully, turn into understanding.

\section{Ruth M. Campbell}

Researcher

Wilson Centre,

Toronto General Hospital

Toronto, Ont.

Acknowledgements: The author thanks the incredible women who sparked this initiative, the dedicated research and photography assistants, Andrea Ortiz and Jennifer Szabo, the transformative editor, A.G. Klei and talented photographer, Kevin Kong.

CMAJ 2013. DOI:10.1503/cmaj.120493 